American Journal of Applied Sciences 4 (12): 1054-1062, 2007

ISSN 1546-9239

(C) 2007 Science Publications

\title{
Decolorization of Remazol Brilliant Blue Dye Effluent by Advanced Photo Oxidation Process $\left(\mathrm{H}_{2} \mathrm{O}_{2} / \mathrm{UV}\right.$ system)
}

\author{
A. S. Mahmoud, M. S. Brooks and A. E. Ghaly \\ Department of Process Engineering and Applied Science, Dalhousie University \\ Halifax, Nova Scotia, Canada B3J 2X4
}

\begin{abstract}
Advanced photo oxidation processes hold great promise for the improved treatment of textile dye effluent. In this study, the effectiveness of a $\mathrm{H}_{2} \mathrm{O}_{2} / \mathrm{UV}$ system for the decolorization of remazol brilliant blue effluent was investigated by examining the optimum conditions for dye removal in two reactors (coil and conventional). The results showed that the coil reactor had a higher temperature profile than the conventional reactor. When the dye was fed into the reactors at $25^{\circ} \mathrm{C}, \mathrm{UV}$ radiation alone was not effective as the decolorization efficiency of the conventional reactor varied from 0.0 to $12.3 \%$, while that of the coil reactor varied from 0.0 to $7.3 \%$, depending on the residence time used. The effect of UV radiation at $100^{\circ} \mathrm{C}$ was also negligible as the maximum decolorization efficiencies were 4.0 and $3.7 \%$ for the conventional and the coil reactors, respectively. Increasing the concentration of $\mathrm{H}_{2} \mathrm{O}_{2}$ increased decolorization efficiencies of both UV reactors. Dye decolorization also increased with residence time. More than 93\% color removal of remazol brilliant blue dye was achieved with a residence time of 56 min and $100 \%$ decolorization achieved in 65 min using a $\mathrm{H}_{2} \mathrm{O}_{2}$ concentration of $12.50 \mathrm{~mL} \mathrm{~L}^{-1}$.
\end{abstract}

Key words: Advanced oxidation, textile wastewater, remazol brilliant blue, reactive dye, $\mathrm{H}_{2} \mathrm{O}_{2}$, UV

\section{INTRODUCTION}

Color in textile effluents has become particularly identified with the dyeing of cotton products and the use of reactive dyes. Up to $30 \%$ of the used dyestuffs remain in the spent dye-bath after the dyeing process ${ }^{[1]}$. The high consumption of reactive dyes, mainly in the cotton industry, causes environmental and aesthetic problems, due to their low degree of exhaustion. A significant percentage $(10-40 \%)$ of the dye remains in its hydrolyzed and unfixed form in the exhausted dye bath or is removed in the washing liquors ${ }^{[2]}$.

Over 700,000 tons of approximately 10,000 types of dyes and pigments are produced annually worldwide, of which about $20 \%$ are in industrial effluents from the textile dyeing and finishing processes ${ }^{[1]}$. Many of these synthetic dyestuffs cannot be treated successfully by conventional methods due to their complex polyaromatic structure and hence cause health problems ${ }^{[3]}$. There is also concern that the aromatic amines, which are formed as metabolites by reductive fission of the azo bond under anaerobic conditions, could pose a more serious toxic hazard than the intact dye molecules ${ }^{[4]}$.
The use of conventional textile wastewater treatment processes imposes new challenges to environmental engineers faced with increasing restrictive effluent quality by water authorities. Conventional treatment such as biological treatment will no longer be acceptable as $53 \%$ of 87 colors are identified as non-biodegradable. Pagga and Brown ${ }^{[4]}$ reported that the residual colour is usually due to insoluble dyes which have low biodegradability such as reactive blue 21 , direct blue 80 and vat violet that have a COD/BOD ratio of 59.0, 17.7 and 10.8, respectively ${ }^{[5]}$. Advanced oxidation processes (AOPs) hold great promise for better treatment of textile dyes $^{[6]}$. The goal of AOPs design is to generate and use hydroxyl free radicals (HO) as strong oxidants to destroy compounds that cannot be oxidized by conventional oxidants $^{[7-10]}$. The versatility of AOP is also enhanced by the fact that they offer different possible ways for generating $\mathrm{OH}^{*}$ radicals. Generation of $\mathrm{OH}^{*}$ is commonly accelerated by combining $\mathrm{O}_{3}$, $\mathrm{H}_{2} \mathrm{O}_{2}, \mathrm{TiO}_{2}$, UV radiation, electron-beam irradiation and ultrasound. Of these, $\mathrm{O}_{3} / \mathrm{H}_{2} \mathrm{O}_{2}, \mathrm{O}_{3} / \mathrm{UV}$ and $\mathrm{H}_{2} \mathrm{O}_{2} / \mathrm{UV}$ hold the greatest promise for oxidizing textile wastewater.

Corresponding Author: Abdel Ghaly, Department of Process Engineering and Applied Science, Dalhousie University, Halifax, Nova Scotia, Canada, B3J 2X4 
The objectives of the study were to investigate the effectiveness of an advanced oxidation process $\left(\mathrm{H}_{2} \mathrm{O}_{2} / \mathrm{UV}\right)$ for decolorization of remazol brilliant blue effluent and to determine the optimum conditions (temperature, residence time, $\mathrm{H}_{2} \mathrm{O}_{2}$ concentration and UV reactor type) for dye removal.

\section{MATERIALS AND METHODS}

Experimental apparatus: The experimental apparatus (Fig. 1) consisted of a dye feeding and effluent removal system, UV reactors, pumps and a data acquisition system.

The dye feeding and effluent removal system consisted of remazol brilliant blue dye feeding tank, a peristaltic pumps and an effluent collection tank. Each of the dye feeding and effluent collection tanks was made of a $4 \mathrm{~mm}$ thick Plexiglas pipe of a $200 \mathrm{~mm}$ internal diameter and a $435 \mathrm{~mm}$ height, giving capacity of about $11 \mathrm{~L}$. The bottom and cover of each tank were made from $4 \mathrm{~mm}$ thick Plexiglas circular plates. The outlet port (4 $\mathrm{mm}$ diameter) of the feeding tank was located at $15 \mathrm{~mm}$ from the bottom. A mixing shelf having stirring blades $(1.5 \mathrm{~mm}$ thick and $72 \mathrm{~mm}$ in length) of $9 \mathrm{~mm}$ diameter and $370 \mathrm{~mm}$ length was installed through the center of the feeding tank cover and used to mix the dye. The shaft was driven by an electric motor (model NSI-1 ORS3, Bodine Electric Company, Chicago, USA.) mounted on top of the feeding tank cover. Two variable speed peristaltic pumps and Masterflex precision tubing (Digi-Staltic, Masterflex Model 7253-60, head model 77200-50, tubing no. MasterFlex® 6404-13, Barnant Company, Division of Cole Parmer Instrument.Co., Barrington, IL.) were used. The peristaltic pumps pumped the material from the feed tank into the UV reactors at the desired flow rate.

Two $380 \mathrm{~mm}$ arc length low pressure mercury lamps, each enclosed in a $21 \mathrm{~mm}$ diameter (OD) quartz tube, were used in two reactors (Fig. 2). The inner and the outer diameter of both reactors are 55 and $61 \mathrm{~mm}$, respectively. A $3 \mathrm{~mm}$ thick stainless steel chamber gave a gap size (distance between the quartz sleeve and the inner surface of reactor casing) of $17 \mathrm{~mm}$ in both reactors. A coil made of stainless steel with a length of $448 \mathrm{~mm}$ a thickness of $0.85 \mathrm{~mm}$, an internal diameter of $21 \mathrm{~mm}$ and a pitch of $20 \mathrm{~mm}$ was used in one reactor. The working volume in each reactor was $840 \mathrm{~mL}$. The outlet of the reactor with coil was $13 \mathrm{~mm}$ higher than the outlet of the reactor without coil to compensate for the volume occupied by the coil.

A digital data logger (Model 4702-5 E, Cole Parmer, Chicago, Illinois) and type $\mathrm{T}$ thermocouples
(Model 8530-75, Cole Parmer instrument company, Chicago, Illinois) were used in the study to measure the temperature in the reactors. The thermocouples were placed at nine locations in each reactor (Fig. 3): (a) the outside surface of the reactor opposite to inlet, (b) the outside surface of the reactor at the mid height, (c) the outside surface of the reactor opposite to outlet, (d) the reactor head space, (e) inside surface of the reactor top, (f) the outside surface of the reactor top, (g) outlet, (h) inlet and (i) the lamp socket surface. The temperature sensors (type $\mathrm{T}$ thermocouples) were calibrated using ice and boiling deionized distilled water. The thermocouples were connected to the data acquisition system individually in different channels and immersed into the ice bath. The thermocouple reading, as temperature in degrees centigrade, was corrected to read zero (offset). The thermocouples were then immersed into the boiling water to correct the upper limit. The accuracy of the thermocouples was found to be $\pm 0.4^{\circ} \mathrm{C}$.

Reagents: The chemicals used in this study included hydrogen peroxide and remazol brilliant blue dye. The hydrogen peroxide $30 \%\left(\mathrm{H}_{2} \mathrm{O}_{2}\right)$ was obtained from Fisher scientific (Ca \# H-325-500, Fisher scientific, Montreal, Quebec, Canada). The remazol brilliant blue dye $\quad \sim 50 \% \quad$ (1-amino-4-[4-(1-sulfonyl-ethyl-2sulfoxy)]-2-(9, 10-anthraquinone)-sulfonic acid; disodium salt) was obtained from Sigma (R8001, Ca \# 22-324-7, Sigma, Oakville, Ontario, Canada). The molecular formula of the dye is $\mathrm{C}_{22} \mathrm{H}_{16} \mathrm{~N}_{2} \mathrm{Na}_{2} \mathrm{O}_{11} \mathrm{~S}_{3}$ and the molecular-structure is shown in Fig. $4^{[11]}$.

Standard curve: To determine the concentration of the remazol brilliant blue dye using the colorimetric techniques, a standard curve was developed from the standard solution of remazol brilliant blue dye according to the procedure described by Mahmoud et $a l{ }^{[12]}$. The standard solution was prepared by dissolving $0.1 \mathrm{~g}$ of the dye in $1000 \mathrm{~mL}$ of distilled deionized water at ambient conditions ( $\mathrm{pH}$ of 7 and a temperature of $25^{\circ} \mathrm{C}$ ). Then, a set of nine solutions with remazol blue dye concentrations of $10,20,30,40,50,60,70,80$ and $100 \mathrm{mg} \mathrm{L}^{-1}$ were prepared. Finally, the absorbance of the prepared solutions was measured (in triplicates) using spectrophotometer (Spectronic 601, Fisher scientific, Montreal, Quebec, Canada). The absorbance was then plotted against the known remazol blue dye concentrations $\left(\mathrm{mg} \mathrm{L}^{-1}\right)$ as shown in Fig. 5. A blank sample was used to zero the spectrophotometer.

Experimental design: Three sets of experiments were conducted in this study. In the first set of experiments, 


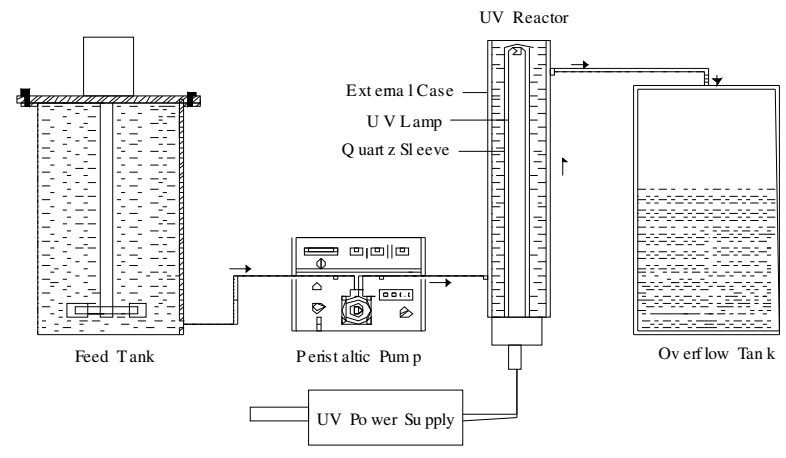

Fig. 1: Experimental setup

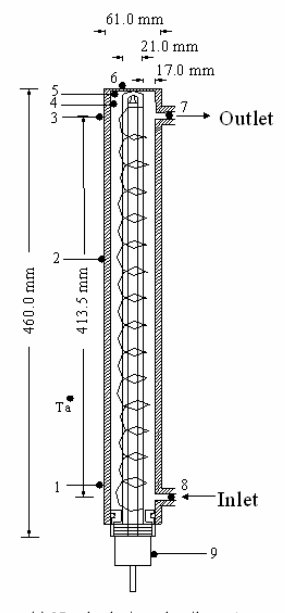

(a) Newly designed coil reactor

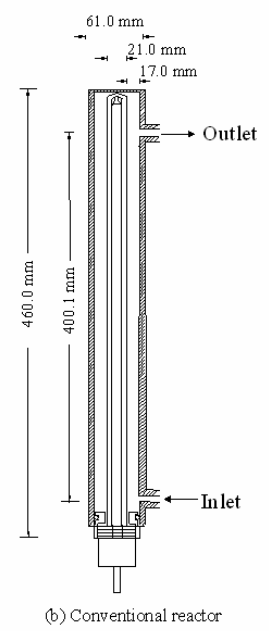

Fig. 2: UV reactors

the performances of the two reactors (coil and conventional) were evaluated at ten residence times (840.0, 168.0, 84.0, 56.0, 42.0, 28.0, 21.0, 16.8, 14.0 and $8.4 \mathrm{~min}$ ) which gave flow rates of $1,5,10,15,20$, $30,40,50,60$ and $100 \mathrm{~mL} \mathrm{~min}^{-1}$ respectively. The dye solution was fed into the reactors at ambient temperature $\left(25^{\circ} \mathrm{C}\right)$. The experiments were run until the steady state temperature was achieved in each reactor before sampling.

The second set of experiments was carried out to study the effect of temperature on the decolorization of remazol brilliant blue using UV radiation. The two UV reactors were operated at the same residence times $(840.0,168.0,84.0,56.0,42.0,28.0,21.0,16.8,14.0$ and $8.4 \mathrm{~min}$ ) and the dye solution was fed into the reactor at $100^{\circ} \mathrm{C}$.

The third set of experiments were carried out to

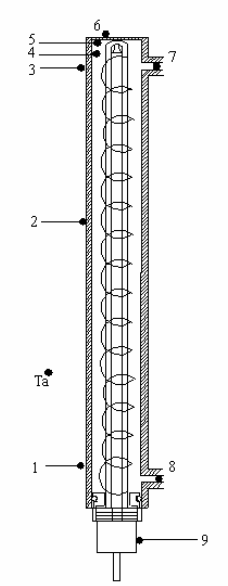

(a) Newly designed coil reactor

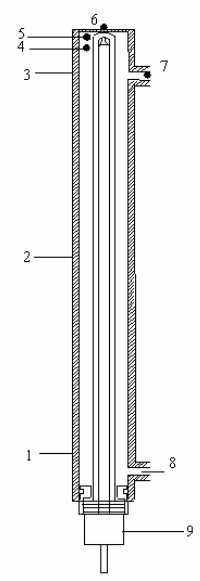

(b) Conventional reactor

1. Temperature on the outside surface of the reactor opposite to inlet.

2. Temperature on the outside surface of the reactor at the mid height.

3. Temperature on the outside surface of the reactor opposite to outlet.

4. Temperature of the reactor head space.

5. The inside temperature of the reactor top.

6. Temperature on the outside surface of the reactor top.

7. The outlet dye temperature.

8. The inlet dye solution temperature.

9. The temperature of the lamp socket surface.

Fig. 3: Location of thermocouples in the two reactors<smiles>Nc1c2c(=O)c3ccccc3c(=O)c2c(Nc2cccc(S(=O)(=O)O[Na])c2)c2c(=O)c3ccccc3c(=O)c12</smiles>

Fig. 4: The molecular-structure of remazol brilliant blue $\mathrm{R}$ dye ${ }^{[11]}$

study the combined effects of using $\mathrm{H}_{2} \mathrm{O}_{2}$ and UV radiation on the decolorization of remazol brilliant blue The two UV reactors were operated at the same residence times $(840.0,168.0,84.0,56.0,42.0,28.0$, $21.0,16.8,14.0$ and $8.4 \mathrm{~min})$. The dye solution was fed into the reactors at ambient temperature $\left(25^{\circ} \mathrm{C}\right)$. Seven concentrations $\left(1,3,6.25,12.5,25,50\right.$ and $\left.75 \mathrm{~mL} \mathrm{~L}^{-1}\right)$ of $\mathrm{H}_{2} \mathrm{O}_{2}(30 \%)$ in the dye solution were investigated. 


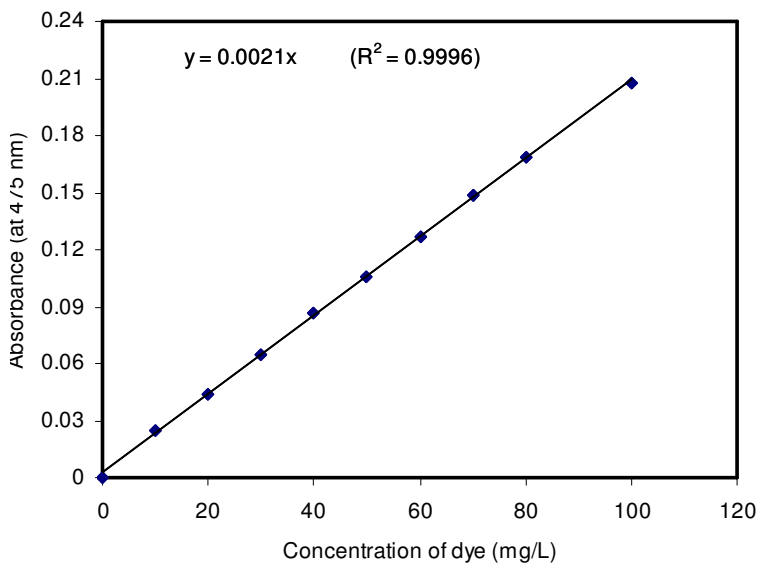

Fig. 5: Standard curve $\left(\mathrm{pH}=7\right.$, temperature $\left.25^{\circ} \mathrm{C}\right)$

Experimental procedure: A $20 \mathrm{~L}$ volume of the remazol brilliant blue dye solution $\left(300 \mathrm{mg} \mathrm{L}^{-1}\right)$ was prepared by dissolving ( $6 \mathrm{~g}$ dye in $20 \mathrm{~L}$ ) in deionized water. The $\mathrm{pH}$ of this solution was 7. The dye solution (with and without $\mathrm{H}_{2} \mathrm{O}_{2}$ ) was pumped through the reactors at the required flow rates using the precalibrated peristaltic pump (Digi-Staltic, Masterflex model 7253-60, head Model 77200-50, tubing no. MasterFlex® 6404-13, Barnant Company, Division of Cole Parmer Instrument. Co., Barrington, IL.), while the UV lamp was on. After the reactor was filled with dye solution, it was left to reach steady state (constant temperature). The temperature readings were noted down from the data logger. Samples were collected during the steady state from the reactor outlet. The absorbance of the dye solution samples was measured using a spectrophotometer (Spectronic 601, Fisher scientific, Montreal, Quebec, Canada) at a wave length of $475 \mathrm{~nm}$.

\section{RESULTS AND DISCUSSION}

Reactor temperature: The measured steady state temperatures at different flow rates (residence times) for the conventional and coil reactors when fed the dye at temperatures of $25^{\circ} \mathrm{C}$ and $100^{\circ} \mathrm{C}$ are shown in Tables 1 and 2 . The temperatures at all locations in the reactors decreased with the decrease in the residence time, except for the influent temperature (location 8), which remained constant. Generally, the temperatures measured close to the bottom of the reactors were less than the temperatures measured at the top. This was due to the dye being fed at the bottom of the reactor and picking up heat from the UV lamp as it traveled upward to the outlet.

When the dye was fed at $25^{\circ} \mathrm{C}$, the steady state effluent temperature decreased from $40.4^{\circ} \mathrm{C}$ to $29.3^{\circ} \mathrm{C}$ and from $41.5^{\circ} \mathrm{C}$ to $30.2^{\circ} \mathrm{C}$ in the conventional reactor and the coil reactor as the residence time was decreased from 840.0 to $8.4 \mathrm{~min}$, respectively. When the dye was fed at $100{ }^{\circ} \mathrm{C}$, the steady state effluent temperature decreased from $117.7{ }^{\circ} \mathrm{C}$ to $111.0{ }^{\circ} \mathrm{C}$ and from 122.7 ${ }^{\circ} \mathrm{C}$ to $111.0^{\circ} \mathrm{C}$ in the conventional reactor and the coil reactor as the residence time was decreased from 840.0 to $56.0 \mathrm{~min}$, respectively. It was also noticed that the temperatures measured at all the locations in the coil reactor were higher than those measured at similar locations in the conventional reactor. The coil absorbs the heat generated from the UV lamp and increases the heat transfer to the fluid causing higher temperatures.

The results obtained from the present study indicated that increased temperature (from $25^{\circ} \mathrm{C}$ to $100^{\circ} \mathrm{C}$ ) reduced the decolorization efficiency of the UV reactors. Zeynep and Filiz ${ }^{[13]}$ reported that increasing the temperature from $15^{\circ} \mathrm{C}$ to $50^{\circ} \mathrm{C}$ did not change the decolorization efficiency for reactive yellow 15 by Fenton's oxidation. Galindo and Kalt ${ }^{[14]}$ reported that the temperature did not significantly affect the decolorization of textile dye by UV radiation and that the photochemical reactions are effectively not sensitive to small changes in temperature in the range $22-45^{\circ} \mathrm{C}$. This is due to the fact that photochemically induced reactions often have a low activation energy ${ }^{[15]}$.

Effect of UV radiation: Figure 6 shows the decolorization efficiencies of the two reactors when the dye was fed at 25 and $100^{\circ} \mathrm{C}$. When the dye was fed at $25^{\circ} \mathrm{C}$, the decolorization efficiency of the conventional reactor varied from 0.0 to $12.3 \%$, while that of the coil reactor varied from 0.0 to $7.3 \%$, depending on the residence time used. Although the decolorization increased with increasing the residence time, the results showed that UV radiation was not effective in destroying the dye when it was fed into the reactor at room temperature $\left(25^{\circ} \mathrm{C}\right)$. There was also a negligible effect of UV radiation on the decolorization of remazol brilliant blue in aqueous solution fed into the reactors at $100^{\circ} \mathrm{C}$ as the maximum decolorization efficiencies were 4.0 and $3.7 \%$ for the conventional and the coil reactors, respectively.

The UV dosage applied to a wastewater is determined by the intensity of the UV radiation and the contact time involved and is commonly expressed in milliwatt-sec per square centimeter $\left(\mathrm{mW}-\mathrm{sec} \mathrm{cm}^{-2}\right)$. Ultraviolet lamps are classified as low, medium or high pressure units ${ }^{[16]}$. The low pressure UV lamps are usually 14 - 35 watts ${ }^{[17-19]}$. The lamps used in this study were 15 watt. Reported studies in the literatures indicated both successes and failures of UV for decolorizing wastewaters. With the exception of 
Am. J. Appl. Sci., 4 (12): 1054-1062, 2007

Table 1: Steady state temperatures at different locations when the dye was fed into the reactors at $25^{\circ} \mathrm{C}$

\begin{tabular}{|c|c|c|c|c|c|c|c|c|c|c|c|c|c|c|c|c|c|c|}
\hline \multirow{3}{*}{$\begin{array}{l}\text { Residence } \\
\text { time (min) }\end{array}$} & \multicolumn{18}{|c|}{ Location of thermocouples } \\
\hline & \multicolumn{2}{|c|}{1} & \multicolumn{2}{|c|}{2} & \multicolumn{2}{|c|}{3} & \multicolumn{2}{|c|}{4} & \multicolumn{2}{|c|}{5} & \multicolumn{2}{|c|}{6} & \multicolumn{2}{|c|}{7} & \multicolumn{2}{|c|}{8} & \multicolumn{2}{|c|}{9} \\
\hline & A & B & A & B & A & B & A & B & A & B & A & B & A & B & A & B & $\mathrm{A}$ & B \\
\hline 840.0 & 34.7 & 35.7 & 34.8 & 38.6 & 40.2 & 41.5 & 36.5 & 37.7 & 36.2 & 37.9 & 36.2 & 37.6 & 40.4 & 41.5 & 24.1 & 24.1 & 37.4 & 37.3 \\
\hline 168.0 & 34.1 & 35.6 & 34.5 & 37.5 & 38.5 & 40.0 & 34.8 & 37.5 & 34.6 & 37.4 & 34.4 & 37.3 & 38.6 & 39.7 & 24.0 & 24.0 & 37.2 & 37.2 \\
\hline 84.0 & 32.0 & 35.3 & 32.4 & 36.9 & 37.5 & 38.2 & 34.5 & 36.6 & 34.6 & 36.9 & 34.7 & 37.2 & 37.8 & 38.2 & 24.0 & 24.0 & 36.8 & 36.6 \\
\hline 56.0 & 31.5 & 31.8 & 32.0 & 35.1 & 37.1 & 37.7 & 33.7 & 36.2 & 33.6 & 36.8 & 33.5 & 37.2 & 37.1 & 37.7 & 24.0 & 24.0 & 35.6 & 35.5 \\
\hline 42.0 & 30.6 & 30.9 & 31.8 & 34.2 & 36.3 & 36.7 & 33.2 & 36.0 & 33.4 & 35.7 & 33.2 & 35.8 & 36.4 & 36.9 & 23.2 & 23.2 & 33.3 & 33.0 \\
\hline 28.0 & 29.0 & 29.7 & 30.5 & 33.3 & 35.7 & 36.0 & 32.0 & 34.5 & 32.2 & 33.9 & 31.9 & 34.0 & 35.8 & 36.1 & 23.4 & 23.4 & 31.9 & 31.8 \\
\hline 16.8 & 27.5 & 27.5 & 26.9 & 31.8 & 33.0 & 33.4 & 29.7 & 32.9 & 29.6 & 32.7 & 30.0 & 32.8 & 33.2 & 34.6 & 23.2 & 23.2 & 29.6 & 29.6 \\
\hline 14.0 & 26.0 & 26.8 & 26.4 & 29.0 & 31.4 & 32.8 & 27.9 & 31.2 & 28.8 & 31.6 & 26.9 & 31.8 & 31.6 & 32.9 & 23.0 & 23.0 & 29.3 & 29.6 \\
\hline 8.4 & 25.5 & 26.1 & 25.3 & 27.0 & 28.8 & 29.3 & 26.4 & 30.5 & 27.4 & 31.0 & 26.2 & 30.6 & 29.3 & 30.2 & 22.3 & 22.3 & 28.5 & 28.9 \\
\hline
\end{tabular}

1 is temperature on the outside surface of the reactor opposite to inlet.

2 is temperature on the outside surface of the reactor at the mid height.

3 is temperature on the outside surface of the reactor opposite to outlet.

4 is temperature of the reactor head space.

5 is the inside temperature of the reactor top.

6 is temperature on the outside surface of the reactor top.

7 is the outlet dye temperature.

8 is the inlet dye solution temperature.

9 is the temperature of the lamp socket surface.

$\mathrm{A}$ is the conventional reactor

$\mathrm{B}$ is the coil reactor

Table 2: $\quad$ Steady state temperatures at different locations when the dye was fed into the reactors at $100^{\circ} \mathrm{C}$

\begin{tabular}{|c|c|c|c|c|c|c|c|c|c|c|c|c|c|c|c|c|c|c|}
\hline \multirow{3}{*}{$\begin{array}{l}\text { Residence } \\
\text { time } \\
(\mathrm{min})\end{array}$} & \multicolumn{18}{|c|}{ Location of thermocouples } \\
\hline & \multicolumn{2}{|c|}{1} & \multicolumn{2}{|c|}{2} & \multicolumn{2}{|c|}{3} & \multicolumn{2}{|c|}{4} & \multicolumn{2}{|c|}{5} & \multicolumn{2}{|c|}{6} & \multicolumn{2}{|c|}{7} & \multicolumn{2}{|c|}{8} & \multicolumn{2}{|c|}{9} \\
\hline & $\mathrm{A}$ & B & A & B & A & B & A & B & A & B & A & B & A & B & A & B & A & B \\
\hline 840.0 & 116.4 & 117.5 & 117.6 & 118.3 & 117.7 & 119.3 & 113.1 & 119.9 & 112.6 & 116.4 & 110.2 & 115.0 & 117.7 & 122.7 & 100 & 100 & 48.8 & 48.8 \\
\hline 168.0 & 115.8 & 117.3 & 116.8 & 117.5 & 117.0 & 118.5 & 110.8 & 116.1 & 111.2 & 115.6 & 110.0 & 114.9 & 116.9 & 120.5 & 100 & 100 & 48.4 & 48.5 \\
\hline 84.0 & 114.8 & 113.1 & 115.9 & 116.6 & 116.4 & 117.6 & 110.2 & 115.1 & 110.4 & 113.7 & 110.0 & 113.8 & 116.7 & 119.2 & 100 & 100 & 46.8 & 46.9 \\
\hline 56.0 & 112.5 & 114.0 & 114.8 & 115.7 & 114.8 & 116.2 & 110.0 & 114.2 & 110.0 & 113.0 & 109.5 & 110.1 & 115.0 & 118.8 & 100 & 100 & 46.1 & 46.3 \\
\hline 42.0 & 111.6 & 111.4 & 113.8 & 114.2 & 114.0 & 115.2 & 110.0 & 114.0 & 110.0 & 113.0 & 109.4 & 110.1 & 114.5 & 116.0 & 100 & 100 & 46.0 & 46.7 \\
\hline 28.0 & 110.0 & 110.8 & 112.5 & 113.3 & 113.2 & 114.0 & 110.0 & 113.5 & 110.0 & 112.8 & 109.1 & 109.8 & 113.5 & 115.0 & 100 & 100 & 45.4 & 45.5 \\
\hline 21.0 & 109.0 & 109.6 & 111.5 & 111.9 & 112.5 & 113.1 & 110.0 & 113.0 & 109.4 & 112.6 & 108.9 & 109.5 & 112.9 & 114.0 & 100 & 100 & 45.3 & 45.4 \\
\hline 16.8 & 107.1 & 107.8 & 110.0 & 110.4 & 111.9 & 112.0 & 110.0 & 112.5 & 109.1 & 112.1 & 108.4 & 109.2 & 112.0 & 113.2 & 100 & 100 & 45.1 & 45.0 \\
\hline 14.0 & 106.0 & 106.9 & 108.4 & 109.0 & 110.3 & 111.8 & 109.0 & 112.1 & 109.0 & 111.8 & 108.2 & 108.7 & 111.6 & 112.0 & 100 & 100 & 45.0 & 44.9 \\
\hline 8.4 & 105.0 & 105.2 & 107.0 & 107.8 & 108.2 & 109.4 & 109.0 & 111.3 & 108.9 & 111.5 & 107.9 & 108.0 & 111.0 & 111.2 & 100 & 100 & 44.8 & 44.7 \\
\hline
\end{tabular}

1 is temperature on the outside surface of the reactor opposite to inlet.

2 is temperature on the outside surface of the reactor at the mid height.

3 is temperature on the outside surface of the reactor opposite to outlet.

4 is temperature of the reactor head space.

5 is the inside temperature of the reactor top.

6 is temperature on the outside surface of the reactor top.

7 is the outlet dye temperature.

8 is the inlet dye solution temperature.

9 is the temperature of the lamp socket surface.

$\mathrm{A}$ is the conventional reactor

$\mathrm{B}$ is the coil reactor

Reactive Black 5, significant decolorization of reactive dyes (with concentrations ranging from 100-300 mg $\mathrm{L}^{-1}$ ) has been achieved at various UV intensities and contact times ${ }^{[18,20]}$. Liao et al. ${ }^{[19]}$ reported on a textile wastewater color (420 ADMI units) that was reduced nearly $20 \%$ (from 160 to $128 \mathrm{mg} \mathrm{L}^{-1}$ ) after $40 \mathrm{~min}$ exposure to UV generated with a 14 watt lamp. On the other hand, studies by Ince and Gonenc ${ }^{[21]}$ and Shu et al. ${ }^{[17]}$ indicated that the decolorization of Remazol Black $5\left(40 \mathrm{mg} \mathrm{L}^{-1}\right)$ and Acid Red 1 and Yellow 23 (20 $\mathrm{mg} \mathrm{L}^{-1}$ ) solutions was low when they were exposed to UV radiation.
The remazol brilliant blue dye $\left(\mathrm{C}_{22} \mathrm{H}_{16} \mathrm{~N}_{2} \mathrm{Na}_{2} \mathrm{O}_{11} \mathrm{~S}_{3}\right)$ is an organic aromatic compound containing anthraquinone and amino, sulfonyl, ethyl, sulfoxy groups and sulfonic acid disodium salt ${ }^{[1]}$. Organic compounds (containing carbon) are affected by light and other forms of electromagnetic radiation due to their chemical structure. The degradation process of organic compounds involves the formation of free radicals (short-lived atoms or groups of atoms which are formed by homolytic fission of a covalent bond) and their subsequent reactions as shown in Fig. $7^{[22]}$. These reactions include: auto-oxidation reactions which 
Am. J. Appl. Sci., 4 (12): 1054-1062, 2007

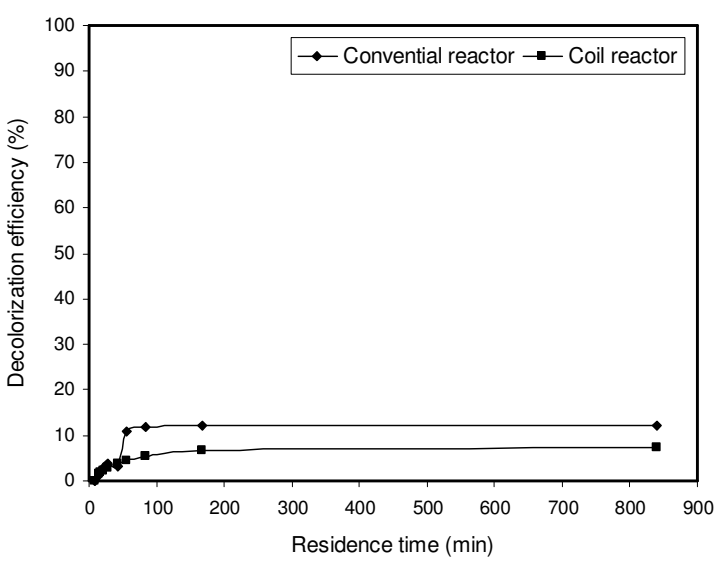

(a) at $25^{\circ} \mathrm{C}$

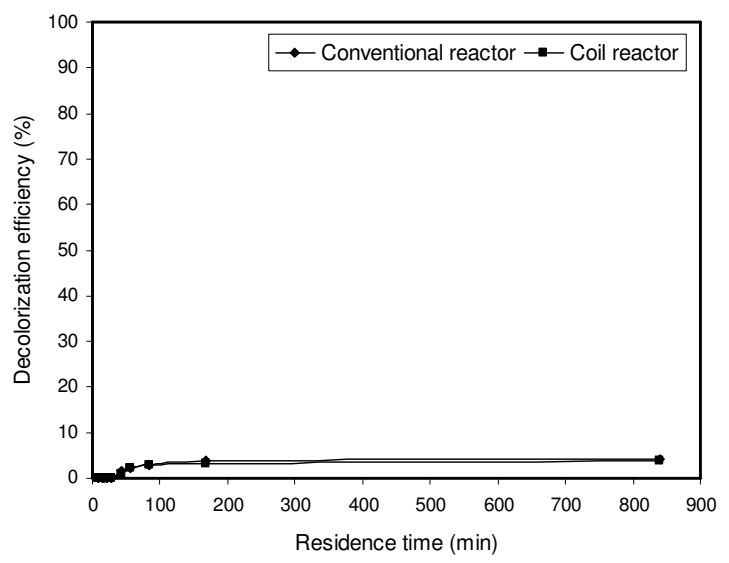

(b) at $100^{\circ} \mathrm{C}$

Fig. 6: Effect of UV radiation on decolorization efficiency using conventional and coil reactors

involve the gain of oxygen, loss of hydrogen, or loss of electrons. They occur when covalent bonds (3) absorb radiation of a specific wavelength corresponding to the amount of energy necessary to displace an electron (known as the bond dissociation energy). Certain groups are highly reactive and promote oxidation, such as double bonds between carbon atoms $(\mathrm{C}=\mathrm{C})$, carbonyl groups $(>\mathrm{C}=\mathrm{O})$ and tertiary hydrogen atoms $(>\mathrm{C}-)$. The reactions terminate when free radicals react together to form stable molecules. These reactions lead to products containing polar groups (e.g. hydroxyl, carbonyl and carboxylic acids) and the formation of conjugated systems. Some dyes require a relatively large input of energy to dissociate bonds while others require less energy to dissociate bonds which make them far more vulnerable to $\mathrm{UV}^{[23,24]}$.

Effect of hydrogen peroxide: Figure 8 shows the combined effects of UV and $\mathrm{H}_{2} \mathrm{O}_{2}$ on decolorization of remazol brilliant blue at various residence times and
$\mathrm{H}_{2} \mathrm{O}_{2}$ concentrations. The results indicated that decolorization increased when the $\mathrm{H}_{2} \mathrm{O}_{2}$ concentration increased. Without $\mathrm{H}_{2} \mathrm{O}_{2}$ (UV only), the maximum decolorization efficiencies obtained at a residence time of $840 \mathrm{~min}$ were $12.3 \%$ for the conventional reactor and $7.3 \%$ for the coil reactor. With the addition of $\mathrm{H}_{2} \mathrm{O}_{2}$ the decolorization efficiency reached $100 \%$ for both reactors.

Analysis of variance was performed on the decolorization efficiency using SPSS 14.0 (SPSS Inc., Chicago, IL) as shown in Table 3. Duncan's multiple range test was also performed on the data in order to test the differences among the levels of each factor as shown in Table 4. This statistical analysis showed that the reactor type, residence time and addition of $\mathrm{H}_{2} \mathrm{O}_{2}$ have significant effects on the decolorization efficiency of the dye. There were also significant interactions between the factors.

Table 5 shows the minimum and maximum decolorization efficiency of the conventional and coil reactors at various $\mathrm{H}_{2} \mathrm{O}_{2}$ concentrations. The results showed that increasing the concentration of $\mathrm{H}_{2} \mathrm{O}_{2}$ increased both the minimum and maximum decolorization efficiencies of both reactors. However, 99.9\% decolorization efficiency can be obtained by using $12.5 \mathrm{~mL} \mathrm{~L}^{-1} \mathrm{H}_{2} \mathrm{O}_{2}$. Ince et al. ${ }^{[21]}$ also showed that decolorization increased when the $\mathrm{H}_{2} \mathrm{O}_{2}$ concentration was increased, but only to some point beyond which no further decolorization occurred. At increased $\mathrm{H}_{2} \mathrm{O}_{2}$ concentrations, the excess can react with hydroxyl radicals already in solution to form water and oxygen ${ }^{[18,}$ ${ }^{21]}$. The results obtained from both reactors also showed that dye decolorization increases when the residence time is increased. More than $93 \%$ color removal of remazol brilliant blue dye is achieved with a residence time of $56 \mathrm{~min}$ and a complete decolorization can be achieved in 65 min using $\mathrm{H}_{2} \mathrm{O}_{2}$ concentration of 12.50 $\mathrm{mL} \mathrm{L}{ }^{-1}$. Previous research revealed that sufficient reaction time for dye removal using $\mathrm{H}_{2} \mathrm{O}_{2} / \mathrm{UV}$ process was found to be subjective. Complete destruction of reactive dyes in 30-90 $\mathrm{min}$ have been recorded ${ }^{[25-28]}$. Percowski and $\mathrm{Kos}^{[29]}$ documented more than 99\% color reduction of dye house wastewater after $2 \mathrm{hrs}$. Shyh-Fang et al. ${ }^{[30]}$ stated that longer reaction times are more advantageous for color removal. They reported 9\% color removal in $10 \mathrm{~min}$ and complete color removal in $120 \mathrm{~min}$.

The decolorization mechanism using UV/ $\mathrm{H}_{2} \mathrm{O}_{2}$ may follow two steps. The ultraviolet light (UV) causes the dissociation of the $\mathrm{H}_{2} \mathrm{O}_{2}$ into two hydroxyl radicals $(\mathrm{OH})$ as follows:

$$
\mathrm{H}_{2} \mathrm{O}_{2} \stackrel{\mathrm{UV}}{\longrightarrow} 2 \mathrm{OH}^{\bullet}
$$




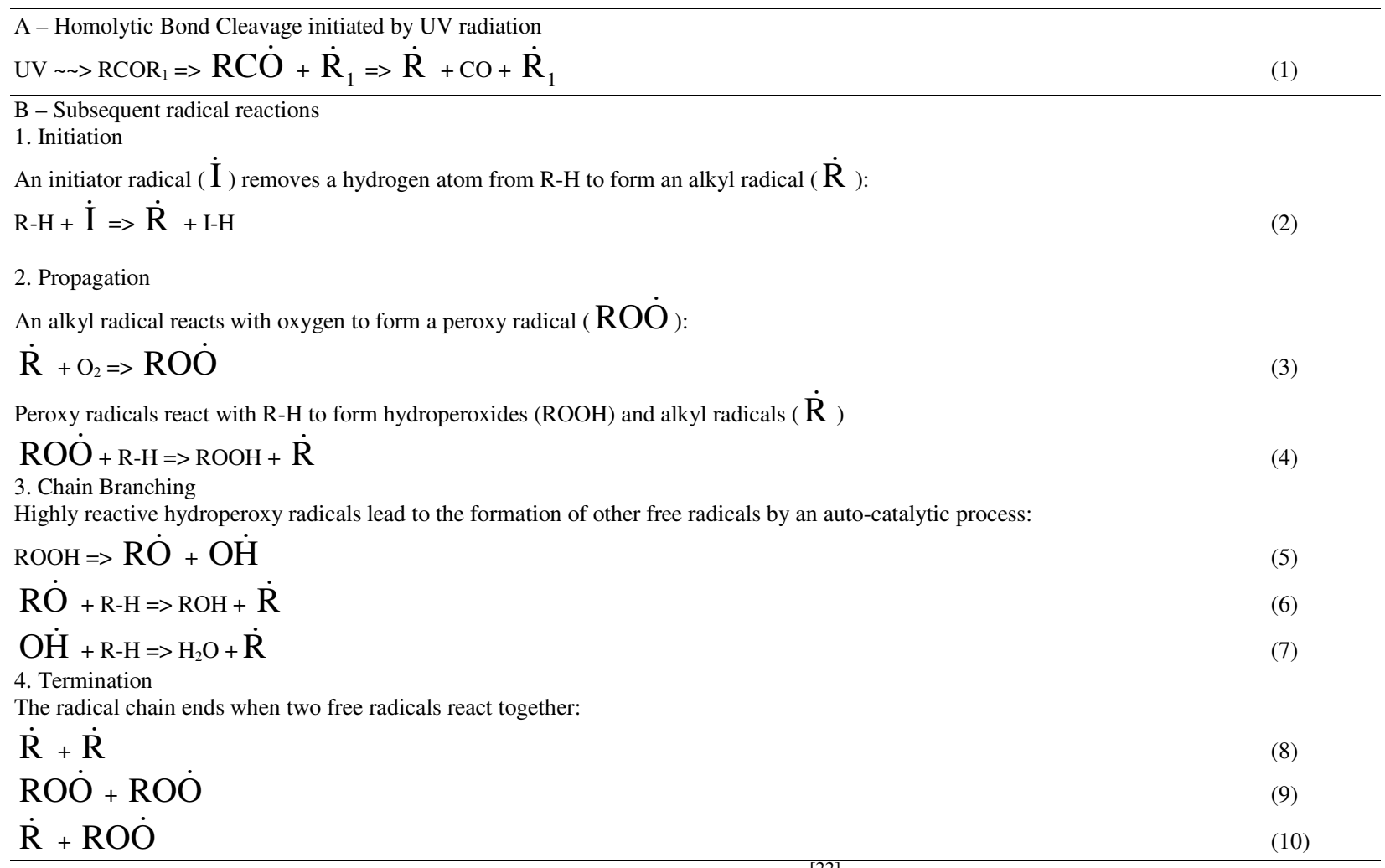

Fig. 7: Homolytic bond cleavage and subsequent radical reactions ${ }^{[22]}$

The hydroxyl radicals are strong oxidants that can readily oxidize organic compounds ${ }^{[21]}$. The radicals degrade organic compounds by separating protons to yield organic radical compounds, which lead to either an abstraction of hydrogen atoms or addition to double bonds ${ }^{[31]}$. Colonna et al. ${ }^{[2]]}$ reported that applying $\mathrm{UV} / \mathrm{H}_{2} \mathrm{O}_{2}$ on dyes containing anthraquinone and sulfonated naphthol rings suggests that nitrogen is evolved at an earlier stage and the azo group and the sulphonic groups are replaced by hydroxyl groups forming polyhydrixylated species. Continuing photoxidation may lead to quinine type compounds and later to aromatic ring cleavage and in the end the main degradation products are sulphate, nitrate, formate and oxalate. When the oxidation is complete, organic compounds end up as $\mathrm{CO}_{2}^{[33,34]}$. Therefore, the equation for complete oxidation of remazol brilliant blue dye can be written as follows:

$$
\begin{gathered}
{\left[\mathrm{C}_{22} \mathrm{H}_{16} \mathrm{~N}_{2} \mathrm{Na}_{2} \mathrm{O}_{11} \mathrm{~S}_{3}\right]+\mathrm{OH}^{\cdot} \rightarrow \mathrm{CO}_{2 \text { (gas) }}+} \\
\left(\mathrm{H}_{2} \mathrm{O}+\mathrm{NO}_{3}^{-}+2 \mathrm{Na}^{+}+\mathrm{SO}_{4}^{-}\right)_{\text {solution }}
\end{gathered}
$$

\section{CONCLUSION}

$\mathrm{H}_{2} \mathrm{O}_{2} / \mathrm{UV}$ treatment for the decolorization of remazol brilliant blue effluent was investigated by examining the optimum conditions for dye removal in two types of reactor. A higher steady state temperature profile was observed in the coil reactor compared to the conventional reactor. When the dye was fed into the reactors at $25^{\circ} \mathrm{C}$, the decolorization efficiency of the conventional reactor varied from 0.0 to $12.3 \%$, while that of the coil reactors varied from 0.0 to $7.3 \%$. At $100^{\circ} \mathrm{C}$, the effect of UV radiation was also negligible as the maximum decolorization efficiencies were 4.0 and $3.7 \%$ for the conventional and the coil reactors, respectively. Increasing the concentration of $\mathrm{H}_{2} \mathrm{O}_{2}$ increased the decolorization efficiencies of both UV reactors. Dye decolorization also increased with residence time. More than $93 \%$ color removal of remazol brilliant blue dye was achieved with a residence time of $56 \mathrm{~min}$ and $100 \%$ decolorization achieved in 65 min using a $\mathrm{H}_{2} \mathrm{O}_{2}$ concentration of 12.50 $\mathrm{mL} \mathrm{L}^{-1}$. The exceptional performance of the combined $\mathrm{H}_{2} \mathrm{O}_{2} / \mathrm{UV}$ treatment may be attributed to greater 1060 


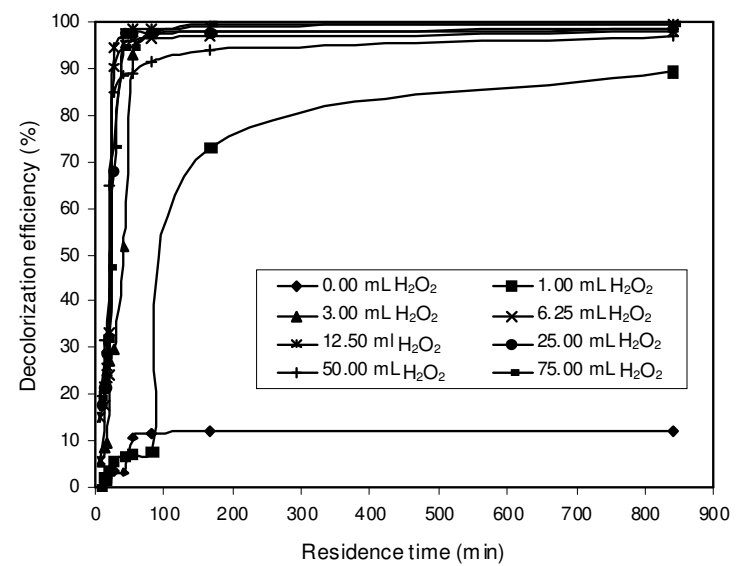

a.

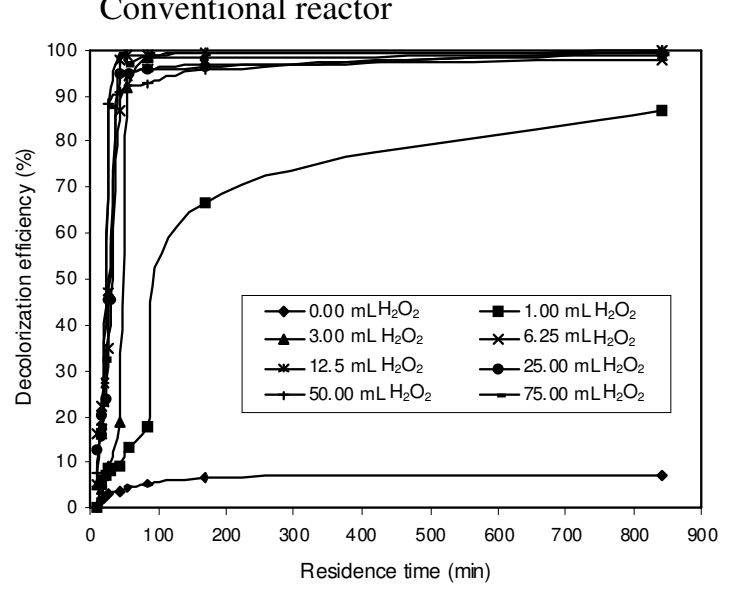

b. Coil reactor

Fig. 8: Combined effects of UV radiation and $\mathrm{H}_{2} \mathrm{O}_{2}$ on decolorization efficiency of remazol brilliant blue

Table 3: Analysis of variance

\begin{tabular}{|c|c|c|c|c|c|}
\hline Source & DF & SS & MS & $\mathrm{F}$ & $\mathrm{P}$ \\
\hline Total & 497 & 784689.1 & & & \\
\hline Model & 159 & 784296.1 & & & \\
\hline $\mathrm{R}$ & 1 & 3254.7 & 3254.7 & 2649.41 & 0.001 \\
\hline \multirow{2}{*}{$\mathrm{T}$} & 9 & 415534.6 & 46170.5 & 37584.11 & 0.001 \\
\hline & 7 & 233465.5 & 33352.2 & 27149.65 & 0.001 \\
\hline $\mathrm{R} * \mathrm{~T}$ & 9 & 1795.4 & 199.5 & 162.39 & 0.001 \\
\hline $\mathrm{R} * \mathrm{H}$ & 7 & 1251.9 & 178.8 & 145.58 & 0.001 \\
\hline $\mathrm{T} * \mathrm{H}$ & 63 & 112768.1 & 1790.0 & 1457.09 & 0.001 \\
\hline $\mathrm{R} * \mathrm{~T} * \mathrm{H}$ & 63 & 16225.9 & 257.6 & 209.66 & 0.001 \\
\hline Error & 320 & 393.1 & 1.2 & & \\
\hline \multicolumn{6}{|c|}{$\mathrm{R}^{2}=98.95$} \\
\hline \multicolumn{6}{|c|}{$\mathrm{CV}=80.03 \%$} \\
\hline \multicolumn{6}{|c|}{$\mathrm{R}=$ Reactor type } \\
\hline \\
\hline \multicolumn{6}{|c|}{$=$ Residence time } \\
\hline
\end{tabular}

oxidation of the dye due to the increased presence of hydroxyl radicals.
Table 4: Differences among the levels of residence time and $\mathrm{H}_{2} \mathrm{O}_{2}$ concentration

\begin{tabular}{lrlrc}
\hline Parameter & Level & $\begin{array}{l}\text { No. of } \\
\text { Observations }\end{array}$ & Mean & $\begin{array}{l}\text { Duncan's } \\
\text { Subset }\end{array}$ \\
\hline Residence time(min) & 8.4 & 48 & 9.16 & $\mathrm{a}$ \\
& 14.0 & 48 & 14.24 & $\mathrm{~b}$ \\
& 16.8 & 48 & 16.86 & $\mathrm{c}$ \\
& 21.0 & 48 & 28.03 & $\mathrm{~d}$ \\
& 28.0 & 48 & 49.03 & $\mathrm{e}$ \\
& 42.0 & 48 & 64.24 & $\mathrm{f}$ \\
& 56.0 & 48 & 75.99 & $\mathrm{~g}$ \\
& 84.0 & 48 & 77.66 & $\mathrm{~g}$ \\
& 168.0 & 48 & 84.04 & $\mathrm{~g}$ \\
$\mathrm{H}_{2} \mathrm{O}_{2}(\mathrm{~mL} / \mathrm{L})$ & 840.0 & 48 & 86.47 & $\mathrm{~g}$ \\
& 0.00 & 60 & 4.86 & $\mathrm{a}$ \\
& 1.00 & 60 & 25.04 & $\mathrm{~b}$ \\
& 3.00 & 60 & 47.89 & $\mathrm{c}$ \\
& 6.25 & 60 & 61.01 & $\mathrm{~d}$ \\
& 25.00 & 60 & 62.94 & $\mathrm{~d}$ \\
& 12.50 & 60 & 65.59 & $\mathrm{~d}$ \\
& 75.00 & 60 & 67.24 & $\mathrm{~d}$ \\
& 50.00 & 60 & 69.99 & $\mathrm{~d}$ \\
\hline
\end{tabular}

Means with the same letter are not significantly different from one another at the 0.05 level.

Table 5: Effect of $\mathrm{H}_{2} \mathrm{O}_{2}$ concentration on decolorization efficiency of remazol brilliant blue

\begin{tabular}{|c|c|c|c|c|}
\hline \multirow[b]{2}{*}{$\begin{array}{l}\mathrm{H}_{2} \mathrm{O}_{2} \\
\text { level } \\
(\mathrm{mL} / \mathrm{L})\end{array}$} & \multicolumn{2}{|c|}{ Conventional reactor } & \multicolumn{2}{|c|}{ Coil reactor } \\
\hline & $\begin{array}{c}\text { Minimum } \\
\text { decolorization } \\
(\%)\end{array}$ & $\begin{array}{c}\text { Maximum } \\
\text { decolorization } \\
(\%)\end{array}$ & $\begin{array}{c}\text { Minimum } \\
\text { decolorization } \\
(\%)\end{array}$ & $\begin{array}{c}\text { Maximum } \\
\text { decolorization } \\
(\%)\end{array}$ \\
\hline 1.00 & 0.0 & 89.3 & 0.0 & 87.1 \\
\hline 3.00 & 5.7 & 98.9 & 5.2 & 99.1 \\
\hline 6.25 & 5.8 & 99.0 & 5.3 & 99.1 \\
\hline 12.50 & 15.3 & 99.8 & 12.6 & 99.9 \\
\hline 25.00 & 18.0 & 98.9 & 13.6 & 99.9 \\
\hline 50.00 & 19.3 & 96.9 & 14.9 & 99.9 \\
\hline 75.00 & 19.6 & 99.9 & 15.7 & 99.9 \\
\hline
\end{tabular}

\section{ACKNOWLEDGMENTS}

This study was financially supported by the National Science and Engineering Research Council (NSERC) of Canada. The postdoctoral fellowship provided by the Egyptian Ministry of Higher Education is highly appreciated.

\section{REFERENCES}

1. Cooper, P. (Ed.), 1995. Color in Dyehouse Effluent. The Society of Dyers and Colorists, Alden Press, Oxford.

2. Lopez, V. and M.C. Gutierrez, 2006. Decolourisation of simulated reactive dye bath effluents by electrochemical oxidation assisted by UV light. Chemosphere, 62: 106-112.

3. Pagga, U. and D. Brown, 1986. The degradation of dye, Behavior of dyestuffs in aerobic biodegradation tests. Chemosphere, 15: 479-491. 
4. Clover, B., 1993. Dyes. Environmental Chemistry. Reprinted from: Kirk- Othmer Encyclopedia of Chemical Technology, 4th Edn., John Wiley \& Sons, Inc. New York, 8: 753-784.

5. Marmagne, O. and C. Coste, 1996. Color removal from textile plant effluents. American Dyestuff Reports, 85: 15-21.

6. Adel, A., A. Idris, S. Katayon and C. Guan, 2004. Treatment of textile wastewater by advanced oxidation processes- A review. Global Nest: The Intl. J., 6: 222-230.

7. Ahmet, B., Y. Ayfer, L. Doris, N. Nese and K. Antonius, 2003. Ozonation of high strength segregated effluents from a woolen textile dyeing and finishing plant. Dyes and Pigments, 58: 93-98.

8. Lidia, S., J. Claudia and N.K. Santosh, 2001. A comparative study on oxidation of disperses dyes by electrochemical process, ozone and hypochlorite and fenton reagent. Water Res., 35: 2129-2136.

9. Stanislaw, L., S. Monika and Z. Renata, 2001. Biodegradation, decolourisation and detoxification of textile wastewater enhanced by advanced oxidation processes. J. Biotechnol., 89): 175-184.

10. Tzitzi, M., D.V. Vayenas and G. Lyberatos, 1994. Pretreatment of textile industry wastewaters with ozone. Water Sci. Technol., 29: 151-160.

11. Patricia, A.C., E.O. Marly, E. Osugi, C.S. Fugivara, N. Boralle, M. Furlan and M. Zanoni, 2005. Evolution of different electrochemical methods on the oxidation and degradation of reactive blue 4 in aqueous solution. Chemosphere, 59: 431-439.

12. Mahmoud, A.S., A.E. Ghaly and S.L. Brooks, 2007. Influence of temperature and $\mathrm{pH}$ on the stability and colorimetric measurement of textile dyes. Am. J. Biotechnol. Biochem., 3: 33-41.

13. Zeynep, E. and N.A. Filiz, 2006. Effect of fenton's reagent on the degradability of CI reactive yellow 15. Coloration Technol., 122: 259-263.

14. Galindo, C. and A. Kalt, 1998. UV- $\mathrm{H}_{2} \mathrm{O}_{2}$ oxidation of monoazo dyes in aqueous media: a kinetic study. Dyes and Pigments, 40: 27-35.

15. Cavert, J.G. and J.N. Pitts, 1966. Photochemistry. New York, JoWiley and Sons, pp: 646.

16. Hanzon, B. and R. Vigilia, 1999. UV Disinfection. Wastewater Technol., 2: 24-28.

17. Shu, H., Y.C.R. Huang and M.C. Chang, 1994. Decolorization of mono - azo dyes in wastewater by advanced oxidation process: A case study of Acid Red 1 and Acid Yellow 23. Chemosphere, 29: 2597-2607.

18. Namboodri, C.G. and W.K. Walsh, 1996. Ultraviolet light/hydrogen peroxide system for decolorizing spent reactive dyebath waste water. American Dyestuff Reporter, pp: 23-28.

19. Liao, C., M. Lu, Y. Yang, I. Lu, 2000. UVcatalyzed hydrogen peroxide treatment of textile wastewater. Environ. Eng. Sci., 17: 9-18.
20. Gregor, K.H., 1992. Oxidative Decolorization of Textile Waste Water with Advanced Oxidative Processes. Peroxid-Chemie GmbH, D-8023 Hollriegelskreuth, FRG.

21. Ince, N.H. and D.T. Gonenc, 1997. Treatability of a textile azo dye by $\mathrm{H}_{2} \mathrm{O}_{2}$-UV. Environ. Technol., 28: 179-185.

22. Ellison, R., 2007. The effects of daylight [online]. Available: www.buildingconservation.com.

23. Mills, J.S. and R. White, 1994. The Organic Chemistry of Museum Objects. 2nd Edn., Butterworth-Heinemann Ltd, Oxford, pp: 73.

24. Thomson, G., 1986. Covalent bonds. The Museum Environment. 2nd Edn., Butterworth-Heinemann Ltd, Oxford, pp: 142.

25. Zhang, F., A.Yediler, X. Liang and A. Kettrup, 2004. Effects of dye additives on the ozonation process and oxidation by-products. A comparative study using hydrolyzed C.I. Reactive Red 120. Dyes and Pigments, 60: 1-7.

26. Georgiou, D., P. Melidis, A. Aivasidis and K. Gimouhopoulos, 2002. Degradation of azo-reactive dyes by ultraviolet radiation in the presence of hydrogen peroxide. Dyes and Pigments, 52: 69-78.

27. Mariana, N., S. Ilie, Y. Ayfer and K. Antonius, 2002. Kinetics of decolorization and mineralization of reactive azo dyes in aqueous solution by $\mathrm{UV} / \mathrm{H}_{2} \mathrm{O}_{2}$ oxidation. Dyes and Pigments, 53: 93-99.

28. Rosario, L.C., G.E. Abel and I.L. Marta, 2002. Photodegradation of an azo dye of the textile industry. Chemosphere, 48: 393-399.

29. Perkowski, J. and L. Kos, 2003. Decolouration of model dye house wastewater with advanced oxidation processes. Fibers and Textiles in Eastern Europe, 11: 67-71.

30. Shyh-Fang, K., L. Chih-Hsiang and H. Hung-Pin, 1999. Peroxidation treatment of dye manufacturing wastewater in the presence of ultraviolet light and ferrous ions. J. Hazard. Mater., 65: 317-333.

31. Cooper, P., 1992. Overview of the effect of environmental legislation on the UK textile wet processing industry, J. Soc. Dyers Colorist, 108: 176-82.

32. Colonna, G.M., T. Caronna, B. Marcandali, 1999. Oxidative degradation of dyes by ultraviolet radiation in the presence of hydrogen peroxide. Dyes and Pigments, 41: 211-220.

33. Tanja, K., M.L.M. Alenka and B.V. Darinka, 2003. Comparison of $\mathrm{H}_{2} \mathrm{O}_{2} / \mathrm{UV}, \mathrm{H}_{2} \mathrm{O}_{2} / \mathrm{O}_{3}$ and $\mathrm{H}_{2} \mathrm{O}_{2} / \mathrm{Fe}^{2+}$ processes for the decoloristion of vinylsulphone reactive dyes. Dyes and Pigments, 58: 245-252.

34. Yang, Y., D.T. Wyatt and M. Bahorshky, 1998. Decolorization of Dyes Using UV/ $\mathrm{H}_{2} \mathrm{O}_{2}$ Photochemical Oxidation. Textile Chemist and Colorist, 30: 27-35. 